\title{
Reconciliación desde la perspectiva bíblica
}

\author{
Reconciliation from a biblical perspective
}

\section{Resumen}

En este trabajo se realiza un acercamiento a la reconciliación desde la perspectiva bíblica. Se estructura en cuatro partes, además de la introducción y conclusión, así: primero, se presentan someramente los diversos conflictos que aparecen narrados en la Sagrada Escritura; segundo, se precisa la terminología bíblica usada para referirse a la reconciliación; tercero, se indican los distintos modelos o paradigmas de reconciliación que se encuentran en la Sagrada Escritura; y finalmente, se señalan los principios bíblicos que posibilitan una reconciliación verdadera e integral.

Palabras claves: reconciliación, Sagrada Escritura, conflictos, paradigmas y principios de la reconciliación, víctimas, memoria, verdad, justicia, perdón.

\section{Abstract}

An approach to the theme of reconciliation is made in this article from the biblical perspective. The essay is organized in four sections, besides the introduction and conclusion. In the first one, the different type of conflicts narrated in the Holy Bible are presented in a summarized way; the second one defines the terminology used in the Bible referred to reconciliation; the third one includes the different models or paradigms of reconciliation founded in the Holy Bible; and the last one, points out the biblical principles that make possible an integral and compete reconciliation.

Keywords: reconciliation, Holy Scripture Bible, conflicts, paradigms and principles of reconciliation, victims, memory, truth, justice, forgiveness.

* Sacerdote, Arquidiócesis de Cali. Estudios de Filosofía en la Universidad Santo Tomás de Aquino, Bogotá. Teólogo y Licenciado en Teología, Pontificia Universidad Javeriana, Bogotá. Magíster en Sagrada Escritura, Pontificio Instituto Bíblico de Roma. Doctor en Teología, Pontificia Universidad Javeriana, Bogotá. Decano de la Facultad de Teología, Filosofía y Humanidades de la Fundación Universitaria Católica Lumen Gentium, Cali, Colombia. Miembro del grupo de investigación Yeshua. Correo electrónico: decateologia@unicatolica.edu.co 


\section{Introducción}

La elaboración teológica en su esfuerzo por ser una verdadera reflexión sistemática de la fe, se desarrolla en tres momentos: primero, parte de la vida misma, en su realidad cotidiana y variada; segundo, la contempla y discierne, a partir de sus fuentes inspiracionales: la Sagrada Escritura, la tradición viva de la Iglesia y, finalmente, el magisterio eclesial; y tercero, relanza al creyente a la vida y a la realidad, generando compromisos prácticos de mejoramiento y transformación de la misma. Aunque la teología latinoamericana ha acuñado esta forma de hacer teología desde el método ver-juzgar-actuar, es innegable que toda sana teología debe partir de la vida y realidad concreta de los seres humanos, dado que "una teología digna de ser considerada [como] tal, brota no de un interés científico y académico, sino de un compromiso humano y preteológico para cambiar y mejorar el mundo" (Vélez, 2004, p. 81).

Es a partir de la premisa anterior, que se hace un acercamiento tanto a la realidad convulsionada y conflictiva de nuestro país, como a los esfuerzos que se vienen haciendo por desarrollar un verdadero proceso de reconciliación integral. Realidad y aspiración se vuelven motores de búsqueda, si se nos permite usar la analogía virtual, para entrar a la Biblia y encontrar allí todo aquello que pueda iluminar y permita reflexionar sobre la necesidad de la reconciliación, problemática tan nueva como nos lo muestra nuestra realidad colombiana, pero a la vez tan antigua como la existencia misma de la humanidad.

A este respecto, es necesario precisar que no todos los temas"modernos" son objeto de tratamiento bíblico. Es decir, que la Biblia no es un manual enciclopédico que tiene respuestas y fórmulas precisas para el abordaje de todos los problemas humanos, pues como bien sabemos, ella nació, se escribió y surgió en y como respuesta a contextos sociales, históricos, culturales, políticos, económicos y religiosos distintos al nuestro, y en los que seguramente, muchas de nuestras problemáticas actuales no aparecían todavía. Lo cual, además, da cuenta del avance, evolución o desarrollo normal de la historia. Pero a la vez, es necesario aclarar que, aunque la Sagrada Escritura no ofrece fórmu- las de solución, precisas y adecuadas a cada una de las problemáticas actuales, ella si nos proporciona criterios básicos para la iluminación de las realidades humanas de todo tiempo, actuando a manera de principio rector de nuestro comportamiento creyente. Con estas consideraciones entramos al tema en cuestión.

\section{Los conflictos bíblicos}

El abordaje del tema de la reconciliación en la Biblia supone, primeramente, acercarse a la realidad humana convulsionada y conflictiva que da origen a la necesidad de la reconciliación. En tal sentido, bien cabe la imagen del espejo (El poblado de la Biblia, s.f), utilizada para referirse a la Sagrada Escritura, indicando que ella no es ajena a nuestra realidad humana, sino que, al contrario, la refleja, la evidencia y la hace objeto de sus líneas. Si se hace una mirada de corrido de la Biblia, teniendo como clave de lectura el conflicto, el lector notará dos cosas: primero, que el conflicto está presente a lo largo de toda la Sagrada Escritura, desde Adán y Eva hasta la pelea contra el dragón del Apocalipsis. Segundo, que esos conflictos son variados, puesto que se refieren a la relación del ser humano con Dios, a la de los seres humanos entre sí, y a la del ser humano con lo creado. En este texto se hará referencia, fundamentalmente, a los conflictos entre los seres humanos, de los cuales se pueden mencionar, brevemente, algunos de los más significativos en la Sagrada Escritura:

Caín y Abel (Gn 4,8); Abraham y Lot (Gn 13,5-11); Abraham y los reyes extranjeros que capturaron a Lot (Gn 14,11-16); Sara y Agar (Gn 16,6-12); Esaú y Jacob (Gn 25-27); la venganza por la deshonra de Dina (Gn 34); José y sus hermanos (Gn 37,12-36); Opresión de Egipto sobre Israel (Ex 1-13); Israel y los pueblos cananeos (Jos y Jc); los hijos de David en la pelea por la sucesión del reino (2 Sam 9-20); las tribus de Israel divididas en dos reinos (1 Re 1112); las luchas internas en ambos reinados (1 Re 13 - 2 Re 17); Israel y los imperios de Asiria, Babilonia, Persia, Grecia y Roma; los judíos que regresaron del exilio y los que se habían quedado en Palestina; los judíos y los samaritanos; helenización de Israel por parte de los seléucidas y la consecuente resistencia armada de los macabeos (1 y 2 Mac); 
los judíos y el imperio romano (zelotes, primera insurrección-destrucción del templo, segunda insurrección-dispersión de los judíos); autoridades religiosas judías y Jesús: crucifixión y muerte; conflictos entre los discípulos de Jesús; judaizantes y gentiles (primera asamblea de Jerusalén); dificultades en las primeras comunidades cristianas (1 Cor 6,1-11), entre otros. De esta revisión general sobre la Sagrada Escritura, se encuentra que no se requiere hacer una búsqueda exhaustiva para encontrar los distintos conflictos presentes en la Biblia.

Varios de esos conflictos exhiben motivos religiosos, que dan cuenta de la ambigüedad del elemento religioso, pues debido a su poder emocional y social, puede ser manipulado tanto desde adentro, como desde fuera. Pero a la vez, lo religioso también puede ser una gran fuente de curación y reconciliación para un pueblo, dándole una visión más amplia del futuro y un modo de hacer las paces con su pasado. Bien dice el analista político Orozco (2002):

Entre los grandes textos que regulan la ética pública, solo la religión se ocupa en serio todavía del problema de la venganza. El hecho de que las llamadas religiones "del libro" estén amarradas a textos originales antiguos que se interpretan y reinterpretan, adaptándose -por vía hermenéutica pero sin perder continuidad- a los cambios sociales y culturales, determina que las mismas no hayan podido escapar fácilmente a la necesidad de reflexionar sobre un motivo tan arcaico y que fuera dominante en el pasado (...) Así se podría explicar el hecho de que el cristianismo, y en general las grandes religiones, a diferencia del derecho y la filosofía moral, hayan conservado viva en la moral pública la preocupación por el talión (Ex 21,22-55; Mt 5,38-39.43-48) y por la revancha, por el odio retributivo y la venganza como destino, por el perdón y la reconciliación (p. 82-83).

\section{Terminología y realidad bíblica de la reconciliación}

La reconciliación aparece referida a lo largo de la Sagrada Escritura, a través de distintos términos hebreos y griegos que tratan de dar cuenta de las diversas aristas de su significado, mediante conceptos tales como: alianza, elección, justicia, redención, misericordia, justificación, pecado, culpa, castigo, expiación, perdón y paz. Este último concepto, expresado a través de la palabra hebrea Shalom, se refiere, en una de sus acepciones, a la meta de la reconciliación, que a su vez implica la justicia. Aunque también la palabra puede referirse al proceso por el cual se logra un pacto o acuerdo, sobre todo cuando tiene que ver con guerras, discordias o casos similares.

Conceptualmente se entiende por reconciliación la renovación de un estado anterior o el restablecimiento de una comunión destruida por la culpa de una o más personas. En sentido propio, la reconciliación en el Antiguo Testamento (AT) designa el acto de Yahveh, con el cual anula el alejamiento entre él e Israel, declarando que él, Yahveh, es nuevamente el Dios de Israel y que Israel puede ser nuevamente por entero su pueblo.

En el Nuevo Testamento (NT), tampoco la palabra "reconciliación" es muy frecuente, y la mayoría de las veces que aparece, se concentra en los escritos paulinos. Sin embargo, esto no significa que no sea importante dentro del mensaje neotestamentario, de hecho es una de las maneras como es interpretada la salvación. El grupo de palabras griegas asociado al significado de reconciliación aparece 15 veces, con predominancia en las cartas de Pablo. El verbo katallasso se emplea seis veces en las cartas paulinas auténticas; se usa una vez para referirse a las relaciones humanas (1 Cor 7: 11), y cinco veces para referirse a las relaciones entre Dios y el hombre (Rom 5: 10 [bis]; 2 Cor 5, 18.19.20). El sustantivo katallage aparece cuatro veces (Rom 5: 11; 11, 15; 2 Cor 5,18.19). El compuesto con doble preposición apokatallasso se halla atestiguado, hasta ahora, únicamente en escritos cristianos; aparece dos veces en Colosenses $(1,20.22)$ y una vez en Efesios $(2,16)$.

La palabra katallasso es una forma compuesta a partir del verbo simple allaso, que significa cambio y canjeo, y de la preposición kata. En el griego se percibe una evolución de la palabra, desde el uso específico de cambiar por dinero, hasta cambiar una cosa por otra; cambio de la enemistad por la amistad; de la hostilidad, la ira o la guerra por la amistad, el amor o la paz; este sentido que es el que permanece. Esta es la palabra técnica que usará San Pablo para referirse tanto al cambio en la 
relación Dios-hombre como a un cambio radical en el estado de vida del ser humano.

Así como constatamos que los conflictos que aparecen en la Sagrada Escritura son variados, también podemos decir que los textos referentes a la reconciliación la presentan en una triple perspectiva: como reconciliación del ser humano con Dios, de los seres humanos entre sí, y del hombre con lo creado. A este respecto, decía Monseñor Renato Raffaele Martino², presidente del Pontificio Consejo de Justicia y Paz, que Cristo ha obrado una triple reconciliación, que constituye para nosotros un manantial inagotable de reflexión sobre la paz y de esfuerzo por la paz: reconciliación interior en las personas salvadas por él, reconciliación externa entre Dios y los hombres y entre los hombres mismos, y reconciliación de los hombres con la creación. Al referirse a la reconciliación interior, plantea que ella penetra la interioridad del espíritu humano y ofrece junto con la gracia, la posibilidad de superar estas pasiones: en primer lugar la de la íntima división, que cada hombre experimenta dentro de sí, entre el ideal al que aspira y aquel que en realidad realiza mediante las propias elecciones y comportamientos.

La reflexión cristiana sobre la reconciliación parte del reconocimiento del hecho fundamental de que Dios nos ha reconciliado con él a través de su hijo Jesucristo, y a su vez nos confió el ministerio de la reconciliación. De acuerdo con San Pablo:

Todo esto procede de Dios, quien nos reconcilió consigo mismo por medio de Cristo, y nos dio el ministerio de la reconciliación; a saber, que Dios estaba en Cristo reconciliando al mundo consigo mismo, no tomando en cuenta a los hombres sus transgresiones, y nos ha encomendado a nosotros la palabra de la reconciliación20. Por tanto, somos embajadores de Cristo, como si Dios rogara por medio de nosotros; en nombre de Cristo os rogamos: ¡Reconcíliense con Dios! (2 Cor 5,18-20).

En el texto, Pablo deja clara la raíz de toda reconciliación, y a su vez hace el llamado para que realmente, como creyentes "reconciliados", ejerzamos el ministerio de la reconciliación. En el pensamiento paulino, el creyente que ha sido reconciliado por Dios por

2 Veáse: Raffaele Martino, M. (2003). Reconciliación y paz. II Congreso Nacional de Reconciliación: La reconciliación, el horizonte de la paz. Documentación de Pastoral Social 196. Conferencia, Bogotá. medio de Jesucristo se convierte en ministro y embajador de la reconciliación recibida. El uso del término "servicio", para designar el ministerio paulino, refleja bien su carácter gratuito: se trata de una experiencia recibida que transforma a su receptor en portador. El creyente reconciliado por medio de Cristo es aquel que ha aceptado responsablemente la iniciativa misericordiosa de Dios y se ha convertido en embajador de la reconciliación recibida, es decir, en agente al servicio de la justicia.

Por tanto, sin descuidar el obvio carácter fontal de la reconciliación religiosa, vamos a centrar la mirada en aquellos textos y/o episodios bíblicos en los que aparece la reconciliación entre los seres humanos, a partir de los distintos escenarios o situaciones en los que las personas interactuamos, tales como las relaciones interpersonales, la vida familiar, las relaciones comunitarias y sociales, la organización social, y las relaciones internacionales.

\section{Paradigmas de reconciliación bíblica entre los seres humanos}

Los textos bíblicos que aluden a la reconciliación entre los seres humanos se pueden agrupar en cinco paradigmas o modelos: el interpersonal; el familiar; el comunitario-social; el estructural y el inter-nacional e inter-cultural.

\section{Paradigma de reconciliación interpersonal}

Este paradigma es rastreable en los textos en los que se legisla sobre los conflictos y el respeto a la vida; la negociación entre Abigail y David (1 Sam 25,2-38); la parábola del perdonado que no perdonó con la invitación al perdón permanente (Mt 18,23-35); el llamado a la actitud de amor al enemigo (Lc 6,27-36); el martirio y perdón de Esteban (Hch 7); y la invitación paulina a devolver bien por mal (Rom 12,14-17), entre otros.

Falsamente se ha pensado que el AT es solamente violencia y odio, y que el NT es plenitud de amor. Sin desconocer que los elementos mencionados están presentes en ambos testamentos, es necesario reconocer que es posible encontrar en toda la Sagrada Escritura ejemplos claros de reconciliación interpersonal. 
Un primer ejemplo es la legislación reguladora de los conflictos y del respeto a la vida. La conocida Ley del Talión (Dt 19,21): “No tengan compasión: cobren vida por vida, ojo por ojo, diente por diente, mano por mano, pie por pie" (Cfr. Ex 21,23-25; Lev 24,1920). El término "talión" deriva de la palabra latina "talis" o "tale", que significa idéntica o semejante, de modo que no se refiere a una pena equivalente sino a una idéntica. Históricamente, constituye el primer intento por establecer una proporcionalidad entre daño recibido en un crimen y daño producido en el castigo, siendo así el primer límite a la venganza, la ley de proporcionalidad, que lejos de revelar una mentalidad vindicativa y bárbara, como se ha dicho a menudo, era un intento de aplicar el principio de equidad a la venganza incontrolada de los particulares, entonces vigente (cf. Gn 4,23-24).

De igual manera, en el libro de Sam $(25,25-35)$ se narra la negociación de Abigail con David para que este no le hiciera caso al desaire y ofensa cometidos por su marido Nabal contra David. En este texto, la negociación establece la posibilidad de una práctica de resolución de conflictos en clave solidaria y no violenta dentro de un horizonte de búsqueda de la justicia. Con la secuencia narrativa de los versículos 23 al 31, el narrador coloca en estilo directo la gestión de Abigail ante David. Ella debe revertir dos errores cometidos por su marido: los agravios verbales a David y la negativa de hospitalidad. Para esto, desplegará diversas estrategias gestuales y verbales: le envía regalos antes de que llegue a visitarlos, y una vez lo ve se baja del burro, postrándose y reconociendo el señorío de David (v.23), así como una permanente auto-referencia como servidora suya (v.24.27.28). La mujer dispone de unos códigos culturales que sabe aprovechar para abrir la posibilidad del diálogo. No se da hasta aquí la condición de paridad necesaria para una auténtica negociación. Pero a lo largo del diálogo ella irá llevándolo hasta un terreno donde su confrontación concluye en la transformación del corazón de David y sus decisiones cambian totalmente.

A la pregunta con respuesta que le hace Pedro a Jesús sobre el número de veces que se debe perdonar, este último le responde con la parábola de aquel hombre a quien le fue perdonada una altísima deuda económica, y que a su vez, él no fue capaz de tener paciencia y compasión con su compañero que le debía una mínima cantidad de dinero. Y por eso termina Jesús
diciendo:"Así también mi Padre celestial hará con ustedes, si no perdonan de corazón cada uno a su hermano" (Mt 18,21-35). Una advertencia en la que muestra que la reconciliación necesariamente pasa por el perdón, como cancelación de deudas y ofensas recibidas.

Otra invitación a la reconciliación interpersonal es la exhortación que hace Jesús al amor al enemigo. En el libro de Levíticus, versículo del 27 al 30, se menciona:

Pero a ustedes los que oyen, les digo: amen a sus enemigos; hagan bien a los que los aborrecen ${ }^{28}$; bendigan a los que los maldicen; oren por los que los vituperan ${ }^{29}$. $\mathrm{Al}$ que te hiera en la mejilla, preséntale también la otra; y al que te quite la capa, no le niegues tampoco la túnica $^{30}$. A todo el que te pida, dale, y al que te quite lo que es tuyo, no se lo reclames ${ }^{36}$. Sean misericordiosos, así como su Padre es misericordioso (Lc. 6: 27-30.36).

En esta exhortación se manifiesta lo típico y revolucionario de la experiencia cristiana que es el amor a los enemigos, mostrando que el perdón es lo único que permite romper el espiral de violencia y venganza. Será tan importante la reconciliación para el Señor Jesús que le dará prioridad sobre el culto. Bien dice el libro de Mateo, capítulo 5:

Por tanto, si estás presentando tu ofrenda en el altar, y allí te acuerdas que tu hermano tiene algo contra $\mathrm{ti}^{24}$, deja tu ofrenda allí delante del altar, y ve, reconcíliate (diallagethi) primero con tu hermano, y entonces ven y presenta tu ofrenda (Mt. 5:23-24).

Y así Jesús se sitúa en la perspectiva profética de Oseas cuando dijo en su oráculo:" porque yo quiero amor, no sacrificio, conocimiento de Dios, más que holocaustos" (Os 6,6). La reconciliación entonces deriva de la fe como un imperativo impostergable.

La exhortación al perdón será reafirmada por San Pablo en Rom 12,14.17:"Bendigan a los que los persiguen; bendigan, y no maldigan ${ }^{17}$. Nunca paguen a nadie mal por mal". Pero fundamentalmente, será el mismo Jesús, con su actitud en la cruz, con la cual ratificará la centralidad del perdón, al suplicarlo al Padre para sus verdugos:"Padre, perdónalos, porque no saben lo que hacen" (Lc 23,34). Igual será la actitud de Esteban, el primer mártir cristiano, que en pleno martirio oraba diciendo:"Señor, no les tomes en cuenta este pecado" (Hch 7,60). 


\section{Paradigma de reconciliación familiar}

Los textos de Esaú y Jacob; José y sus hermanos en el AT, y del Padre misericordioso y los códigos domésticos paulinos revelan, entre otros, ejemplos claros de reconciliación entre hermanos, padre e hijo, y regulación de las relaciones de pareja y de padres e hijos.

Gn 33:4. "Entonces Esaú corrió a su encuentro y lo abrazó, y echándose sobre su cuello lo besó, y lloraron". Esaú que había sufrido por causa de su hermano Jacob, tanto la pérdida de la primogenitura como de la bendición de su padre como hijo mayor, no obstante el dolor inicial y la rabia que pudo sentir, se vence a sí mismo y al ver a su hermano toma la iniciativa de romper la separación establecida y de sanar la herida abierta: corre, lo abraza, lo besa y llora.

Gn 45:2-8.1415.Y José lloró tan fuerte que lo oyeron los egipcios, y la casa de Faraón se enteró de ello ${ }^{3}$. José dijo a sus hermanos: Yo soy José. ¿Vive todavía mi padre? Pero sus hermanos no podían contestarle porque estaban atónitos delante de él ${ }^{4}$.Y José dijo a sus hermanos: Acérquense ahora a mí. Y ellos se acercaron, y él dijo: Yo soy su hermano José, a quien ustedes vendieron a Egipto $^{5}$. Ahora pues, no se entristezcan ni les pese por haberme vendido aquí; pues para preservar vidas me envió Dios delante de ustedes ${ }^{6}$. Porque en estos dos años ha habido hambre en la tierra y todavía quedan otros cinco años en los cuales no habrá ni siembra ni siega $^{7}$. Y Dios me envió delante de ustedes para preservarles un remanente en la tierra, y para guardarles con vida mediante una gran liberación ${ }^{8}$. Ahora pues, no fuisteis ustedes los que me enviaron aquí, sino Dios; y Él me ha puesto por padre de Faraón y señor de toda su casa y gobernador sobre toda la tierra de Egipto. Entonces se echó sobre el cuello de su hermano Benjamín, y lloró; y Benjamín también lloró sobre su cuello ${ }^{15}$. Y besó a todos sus hermanos, y lloró sobre ellos; y después sus hermanos hablaron con él.

José, luego de intentar hacer caer en cuenta a sus hermanos de lo que habían hecho con él, se les descubre, e interpreta lo sucedido como un envío de Dios para preservar la vida del pueblo. Seguramente, el paso del tiempo y su fe en el Señor le fueron llevando a una sanación lenta del dolor causado por la venta como esclavo, y por las dificultades que tuvo que pasar. Después de enviarle la razón a su padre de que viniera a gozar con él de las concesiones que les hacía el faraón, toma la iniciativa de abrazar, besar y llorar con sus hermanos.
Lc 15:20-24.28.31-32.Y cuando todavía estaba lejos, su padre lo vio y sintió compasión por él, y corrió, se echó sobre su cuello y lo besó ${ }^{21}$.Y el hijo le dijo:"Padre, he pecado contra el cielo y ante ti; ya no soy digno de ser llamado hijo tuyo"22 Pero el padre dijo a sus siervos: "Pronto; traed la mejor ropa y vestidlo, y poned un anillo en su mano y sandalias en los pies ${ }^{23}$; y traed el becerro engordado, matadlo, y comamos y regocijémonos ${ }^{24}$; porque este hijo mío estaba muerto y ha vuelto a la vida; estaba perdido y ha sido hallado."Y comenzaron a regocijarse ${ }^{28}$. Entonces él se enojó y no quería entrar. Salió su padre y le rogaba que entrara.Y él le dijo:"Hijo mío, tú siempre has estado conmigo, y todo lo mío es tuyo" 32 ."Pero era necesario hacer fiesta y regocijarnos, porque este, tu hermano, estaba muerto y ha vuelto a la vida; estaba perdido y ha sido hallado".

El padre de la parábola es agredido y ofendido por su hijo menor que al pedirle la herencia le desea la muerte, y luego derrocha su fortuna. Pero a la vez, es desairado por su hijo mayor, que lleno de resentimiento y envidia rechaza la actitud de acogida que ha tenido el padre con su hermano. A ambos sale a buscarlos para que vuelvan, para que entren, para que participen de la fiesta del reencuentro.

Ef 5,22.25.28-30. Las mujeres estén sometidas a sus propios maridos como al Señor ${ }^{25}$ Maridos, amen a sus mujeres, así como Cristo amó a la iglesia y se dio a sí mismo por ella ${ }^{28}$, Así también deben amar los maridos a sus mujeres, como a sus propios cuerpos. El que ama a su mujer, a sí mismo se ama ${ }^{29}$. Porque nadie aborreció jamás su propio cuerpo, sino que lo sustenta y lo cuida, así como también Cristo a la iglesia ${ }^{30}$; porque somos miembros de su cuerpo.

Col 3,18-2218. Mujeres, estén sujetas a sus maridos, como conviene en el Señor ${ }^{19}$. Maridos, amen a sus mujeres y no sean ásperos con ellas ${ }^{20}$. Hijos, sean obedientes a sus padres en todo, porque esto es agradable al Señor ${ }^{21}$. Padres, no exasperen a sus hijos, para que no se desalienten ${ }^{22}$.Siervos, obedezcan en todo a sus amos en la tierra, no para ser vistos, como los que quieren agradar a los hombres, sino con sinceridad de corazón, temiendo al Señor.

Los dos textos anteriores hacen parte de los llamados códigos domésticos. A partir del análisis de la retórica de los mismos, junto con el intento por discernir posibles repuestas a ella entre sus primeros lectores y lectoras, se obtiene que, frente a la estructura patriarcal de la casa-empresa, estos códigos no encarnan una intención, ni provocaron una respuesta de 
rechazo a esta estructura. Ellos enfocan más bien la conducta de las personas dentro del sistema. En cada una de las relaciones entre los pares desiguales, en las instrucciones dirigidas al miembro dominante -el esposo-padre-amo- se nota un retiro de apoyo a su derecho de controlar y explotar a las personas subordinadas a él -esposa, hijos, esclavos y esclavas. En su lugar, los códigos procuran persuadir al esposo-padre-amo que trastorne esa pauta de dominación, que resista los dictados de su cultura y use el poder de su estatus para potenciar a las personas subordinadas a él. Siguiendo la estrategia del autor, es posible que algunos de los lectores hubieran aceptado el reto de este mandato contracultural.

\section{Paradigma de reconciliación comunitario- social}

Los textos del nombramiento de jueces por parte de Moisés, de la relación entre las tribus del norte y del sur, y entre los judíos que regresaron del exilio y los que se habían quedado en Palestina, y del procedimiento de corrección fraterna en las primeras comunidades cristianas, ilustran este paradigma.

Ex 18,13-26. Moisés, por sugerencia de su suegro Jetró elige jueces que le ayuden en la resolución de conflictos del pueblo mientras caminaban por el desierto.

Y enséñales los estatutos y las leyes, y hazles saber el camino en que deben andar y la obra que han de reali$\mathrm{zar}^{21}$. Además, escogerás de entre todo el pueblo hombres capaces, temerosos de Dios, hombres veraces que aborrezcan las ganancias deshonestas, y los pondrás sobre el pueblo como jefes de mil, de cien, de cincuenta $y$ de diez ${ }^{22}$.Y que juzguen ellos al pueblo en todo tiempo; y que traigan a ti todo pleito grave, pero que ellos juzguen todo pleito sencillo. Así será más fácil para ti, y ellos llevarán la carga contigo ${ }^{23}$. Si haces esto, y Dios te lo manda, tú podrás resistir y todo este pueblo por su parte irá en paz a su lugar" (Ex 18,20-23).

Se abre así un procedimiento colegial de resolución de conflictos, basado en que todo el pueblo conociera los estatutos y leyes que regían la vida social, para contribuir a que el pueblo pudiera vivir en paz y recibiera la solución a sus problemáticas.

(Mt 18,15-17.“Y si tu hermano peca, ve y repréndelo a solas; si te escucha, has ganado a tu hermano ${ }^{16}$. Pero si no te escucha, lleva contigo a uno o a dos más, para que toda palabra sea confirmada por boca de dos o tres testigos ${ }^{17}$. Y si rehúsa escucharlos, dilo a la iglesia; y si también rehúsa escuchar a la iglesia, sea para ti como el gentil y el recaudador de impuesto". Se trata del procedimiento de la corrección fraterna, con el espíritu de resolución de conflictos que ya se planteaba en el AT, y que incluso considerando la opción de la ex-comunión, es pensada de manera pedagógica, para que el expulsado sienta deseos de volver a la comunidad.

En las primeras comunidades cristianas se dieron conflictos por varios motivos, que fueron objeto de resolución dialogada y concertada, lo que a la vez ratificaba la identidad cristiana. Uno de esos conflictos que ha dejado huella en los escritos bíblicos fue el que se dio entre los cristianos llamados judaizantes y los cristianos provenientes de la gentilidad, a causa de la exigencia que se le hizo a los nuevos conversos de la gentilidad de que asumieran todas las prácticas y leyes judías. Este problema se deliberó y discutió en el escenario de una asamblea llamada, por algunos, como el primer concilio de Jerusalén, en la que se llegó a una solución consensuada: "Por tanto, yo juzgo que no molestemos a los que de entre los gentiles se convierten a $\operatorname{Dios}^{20}$, sino que les escribamos que se abstengan de cosas contaminadas por los ídolos, de fornicación, de lo estrangulado y de sangre" (Hch 15,19-20).

San Pablo será incisivo en invitar a la resolución de los conflictos en el seno de las mismas comunidades apelando a las propias instancias establecidas en la comunidad para tal efecto (1 Cor 6,1-11).

Dos ejemplos de negociación de conflictos sociales no exitosa, no por la negociación ni la búsqueda misma de la reconciliación, sino por los actores causantes del conflicto, serán la relación entre las tribus del sur y del norte con ocasión de la sucesión del rey Salomón y la relación de los judíos que regresaron del exilio con los judíos que habían permanecido en Palestina. La primera está muy unida al paradigma de la reconciliación estructural, dado que una vez muerto Salomón las tribus del norte le solicitan a Roboam, el nuevo rey, un tratamiento digno y respetuoso en consideración a su condición humana, pero el rey, no atiende la solicitud y al contrario endurece las condiciones hostiles contra las tribus del norte, generando la división del reino en dos (1 Re 12,1-19). En cuanto a la segunda negociación, si bien los libros de Esdras y Nehemías hacen referencia al regreso de los exilia- 
dos, es significativo que se desconozcan los "derechos" de los que habían permanecido en Palestina, y se les trate como impuros e invasores ilegítimos de la tierra. Esto será objeto de discusión, con soluciones la mayoría de las veces a favor de los retornados del exilio, incluso con una perspectiva de lectura de la historia desde este grupo. Este será un antecedente del posterior cisma entre judíos y samaritanos, y del actual conflicto por la tierra santa entre palestinos y judíos.

\section{Paradigma de reconciliación estructural}

Este paradigma hace referencia a la reconciliación de las estructuras sociales, entendido como el cambio de la situación de injusticia, pobreza y desigualdad de la mayoría de la población, para dar paso al establecimiento de unas nuevas, mejores y adecuadas condiciones de vida para todos. Esto se manifiesta en la preocupación bíblica por los pobres y por unas mejores condiciones de vida. Preocupación que es transversal a la Sagrada Escritura, pues aparece a lo largo de los distintos corpus bíblicos. Comenzando con la revelación de Dios a Moisés en la zarza (Ex 3,1-10), hasta la presentación neotestamentaria de Dios revelado en Jesucristo como el pastor que tiene compasión, parte el pan y viene a anunciar liberación, salvación, vista, y el jubileo del Señor (Mc 6,34.41-43; Lc 4,18-19).

Las palabras de Eclo 35,12-21, refiriéndose a Dios como profundamente humano y compasivo, e interesado por los débiles, presentan una imagen que no es aislada en la Biblia, sino que refleja una mentalidad de siglos, contenida en toda clase de tradiciones: cultuales, sapienciales, legislativas y proféticas. Así es como en el período de los jueces, se dan las primeras diferencias sociales y económicas, y correlativamente los primeros esfuerzos por ayudar a los necesitados. Esto aparece en el código de la alianza (Ex 21,22-23,19), donde se expresa la preocupación por los grupos más débiles y pobres, la preocupación por la recta administración de la justicia, la legislación sobre los préstamos, la ley sobre el comercio. Luego vendrán los profetas, que tendrán como uno de los aspectos centrales e importantes de su mensaje, la denuncia de los problemas sociales y su invitación a la construcción de una sociedad más justa. Aspecto que ya era evidente en Israel, desde la sabiduría tribal, el culto y las leyes anteriores a la aparición de los grandes profetas.

Los profetas se preocuparán seriamente por la justicia social, pero cada uno lo hará desde su propio punto de vista, subrayando a veces un problema que otros pasan por alto. Am 3,9-11 es sintomático con su idea de una sociedad aparentemente próspera, que encubre una guerra civil de los ricos contra los pobres, de los que "atesoran" contra los"oprimidos". Oseas constata algo parecido pero lo formula con palabras distintas: "No hay fidelidad, ni afecto, ni conocimiento de Dios en el país; maldición y mentira, asesinato y robo y adulterio se extienden por el país, homicidio, tras homicidio" (Os 4,1-2). Más interesante es el caso de Jerusalén, porque aquí contamos con opiniones muy diversas (Is 1,21-26; Miq. 3,9-11; Sof 3,1-4; Jr 6,1-8; Ez 22,1-16).

Entre los aspectos que los profetas denuncian como obstáculo para una verdadera reconciliación están la divinización de las armas y el culto al poderío militar. Os 1,7; 10,13b; Miq 5,10; Hab 1,16; Zac 4,7. Y por eso cuando anuncian la reconciliación futura uno de los signos que la expresa es el hecho de que las armas se convertirán en instrumentos de trabajo: "Entonces forjarán sus espadas en rejas de arado, y sus lanzas en podaderas. No alzará espada nación contra nación, ni se adiestrarán más para la guerra" (Is 2,4; Miq 4,3).

Esta preocupación social será luego retomada en el NT por el propio Señor Jesús, quien hará de su atención a los pobres y necesitados, punto central de su programa misional (Lc 4,18-19) desarrollado en su vida cotidiana: actuando como buen pastor que enseña y reparte el pan (Mc 6,34.41-43); perdonando a los pecadores, sanando a los enfermos y reintegrándolos a la comunidad; planteando el poder como servicio (Jn 13) y condenando toda búsqueda afanosa de primeros puestos, de poder, de dinero (Mc 9,33-37; 10,23-27; 10,35-45). "Jesús queriendo romper las barreras que dividían a los seres humanos en justos e impíos, sanos y enfermos, satisfechos y hambrientos, entró en conflicto mortal con los enemigos de la reconciliación". 


\section{Paradigma de reconciliación inter-nacional e inter-cultural}

La relación de Israel con otros pueblos siempre fue tensa, debido a la codiciada ubicación geográfica del pueblo bíblico. Tanto los pueblos vecinos, como las grandes potencias o imperios, tendrán que ver de alguna manera con Israel. La primera relación a considerar fue la que tuvieron Egipto e Israel. En tiempos del patriarca José, la relación era buena y respetuosa, hasta el punto de que José era el segundo al mando en Egipto, y tuvo una serie de prerrogativas para su pueblo. Esto cambiará con la muerte de los representantes significativos de ambos pueblos, convirtiéndose en una situación de temor para los egipcios, que pensaban que si los hebreos seguían creciendo, se unirían a sus enemigos y los destruirían. Y en tal sentido, aplicaron contra los hebreos medidas despiadadas de control natal y de opresión desmedida. Por intervención de Yhwh, Moisés será llamado a mediar para que el pueblo pudiera salir al desierto a adorar al Señor. Empieza así un proceso de interlocución y negociación con el faraón, que estaba obsesionado por mantener su dominio opresor. Dios a través de Moisés buscará la manera de que el faraón deje salir al pueblo sin mayores traumatismos. Se lograrán acuerdos parciales que siempre serán incumplidos por el faraón en detrimento de la situación de Israel. Se trataba de una negociación en la que el faraón no tenía ningún interés por cambiar las cosas y revertir el modelo dominador, por eso muchas veces incumplirá su palabra y recurrirá a la mentira. Todo esto tendrá como resultado lo que ya conocemos, el paso del mar rojo con la dos caras de la moneda: liberación para Israel y la derrota de Egipto con el ahogamiento de sus caballos y jinetes.

La otra relación conflictiva fue la del pueblo judío con los seléucidas en cabeza de Antíoco IV Epifanes, quien de manera autoritaria, arbitraria y violenta quiso imponer no solo la dominación política sobre el pueblo, sino también la práctica religiosa: persiguiendo a todos los que observaran fielmente las prescripciones judías. Frente a lo cual, la mayoría de los judíos se mantuvieron fieles a su fe, bien mediante la resistencia armada, bien mediante el martirio. Será la misma actitud arrogante, irrespetuosa e impositiva del mandatario la que socavará las posibilidades de reconciliación. Igual que la actitud de estos dos imperios, será también la de los demás, a saber: Asiria, Babilonia, Persia y Roma. Por tanto, en el plano de las relaciones internacionales, el modelo de reconciliación que la Biblia plantea es más deseado y soñado que realizado. De ahí que los oráculos proféticos canten: la reconciliación entre los pueblos (Is 2,1-5). Y a la vez los profetas advierten contra las alianzas, cuando se pone en ellas, y en los imperios que están detrás, la salvación como si de ellos dependiera. Os 5,12-17; 7,812; 8,8-10; 12,2; 14,4; Is 30,1-5; 31,1-3; Jer 2,18.36; Ez 16,1-27. Los profetas pensaban que cuando el pueblo firmaba un tratado con las grandes potencias, les estaba atribuyendo cualidades divinas, o situándolas en un puesto que solo corresponde a Dios, y de este modo los imperios se convertían en ídolos.

El libro de Jonás presenta de manera novelada la actitud distinta e insólita de uno de esos imperios: Asiria, a través de los habitantes de su capital, Nínive. Jonás, a despecho de su parecer, es enviado por Dios a predicar la conversión en esta gran ciudad, y oh sorpresa, desde los niños hasta los mayores escucharon el llamado, y no recibieron el castigo. Texto que invita a la reconciliación entre pueblos, desde una superación del exacerbado y comprensible nacionalismo judío, para llegar a un universalismo salvífico. De ahí, que en el deuteroisaías Dios llame a Israel a ser"luz de las naciones", no repitiendo la actitud de oscuridad y opresión que los pueblos e imperios tuvieron con ellos. Como lo expresa Issaac,

Poca cosa es que tú seas mi siervo, para levantar las tribus de Jacob y para restaurar a los que quedaron de Israel; también te haré luz de las naciones, para que mi salvación alcance hasta los confines de la tierra (Is 49,6).

Actitud abierta y universalista que tuvo que aprender el mismo Jesús con el episodio desconcertante en el que la cananea le muestra la realidad y la necesidad de una salvación ofrecida para todos. (Mc 7,24-30). Según los evangelistas Lucas y Juan, el Señor Jesús se saldrá de los estrechos márgenes del nacionalismo judío: recordando los episodios salvíficos en favor de Naamán el sirio y la viuda de Sarepta, proponiendo a un samaritano como verdadero prójimo y modelo de agradecimiento, reprendiendo a sus discípulos por querer enviarle fuego del cielo a un pueblo samaritano que no los quiso recibir porque iban camino a Jerusalén, y entablando una larga conversación con una mujer samaritana a quien le revela su identidad mesiánica. 
Esta apertura universal será reforzada por Pablo con su ministerio dirigido principalmente a los gentiles, al defender con radicalidad la participación de aquellos en la Iglesia, sin que tuvieran que pasar por el judaísmo. "Porque nada cuenta ni la circuncisión ni la incircuncisión, sino la creación nueva" (Gal 6,15). Además, el apóstol insistirá en las consecuencias reconciliadoras de Cristo Jesús, que derriba todo muro de separación, estableciendo la paz, y destruyendo cualquier enemistad.

(Ef 2,13-1613. Pero ahora en Cristo Jesús, ustedes, que en otro tiempo estaban lejos, han sido acercados por la sangre de Cristo14. Porque Él mismo es nuestra paz, quien de ambos pueblos hizo uno, derribando la pared intermedia de separación, 15 aboliendo en su carne la enemistad, la ley de los mandamientos expresados en ordenanzas, para crear en sí mismo de los dos un nuevo hombre, estableciendo así la paz16, y para reconciliar con Dios a los dos en un cuerpo por medio de la cruz, habiendo dado muerte en ella a la enemistad.

Pablo irá más allá indicando que la reconciliación sobrepasa todo tipo de barreras: "No hay judío ni griego; no hay esclavo ni libre; no hay hombre ni mujer; porque todos sois uno en Cristo Jesús" (Gal 3:28).

Haciendo este recorrido por los diferentes paradigmas, modos o modelos de reconciliación humana en la Sagrada Escritura, se puede decir, citando a Herr (1994), que lamentablemente, la reconciliación ha sido entendida preponderantemente, en sentido ético individual, como reconciliación del individuo con Dios, mediante el arrepentimiento, la penitencia, la confesión de los pecados y la renovación de la vida cristiana individual. El aspecto ético-social se ha presentado generalmente solo como reconciliación en el ámbito interpersonal entre personas peleadas o enemistadas, pero apenas excepcionalmente como concepción de orden social o político. Sin embargo, tal como señalan las cartas a los Efesios y a los Colosenses, la reconciliación obtenida por Jesucristo posee una dimensión universal y cosmológica. Abarca a todos los hombres, todos los ámbitos de la vida cristiana y también la relación del hombre con la naturaleza.

\section{Principios de la reconciliación desde la perspectiva judeo-cristiana}

Habiendo constatado los distintos textos y paradigmas de reconciliación, es necesario para finalizar precisar algunos principios de reconciliación que se derivan de los mismos textos.

\section{Supresión de las causas del conflicto}

La reconciliación requiere la terminación, eliminación o supresión de las causas que dieron origen a los conflictos. Y por tanto, es necesario conocer bien y atender a esas causas. Bien dice Santiago en su carta: “'De dónde vienen las guerras y los conflictos entre vosotros? ¿No vienen de vuestras pasiones que combaten en vuestros miembros? ${ }^{2}$ Codiciáis y no tenéis, por eso cometéis homicidio. Sois envidiosos y no podéis obtener, por eso combatís y hacéis guerra" (St 4:1-2). Sin superar estas causas profundas y estructurales, la reconciliación es encuentro superficial y espectacular. El conflicto armado de nuestro país, es la expresión de un conflicto más amplio, el conflicto social, económico, político de todos los días, el llamado conflicto estructural que se sostiene en una desigualdad creciente.

Resolver el conflicto atendiendo a sus causas y no eliminando a uno de los adversarios, nos lo ilustra san Pablo en Ef 2,16:"y para reconciliar con Dios a los dos en un cuerpo por medio de la cruz, habiendo dado muerte en ella a la enemistad". El estudio atento de este verso, muestra, en primer lugar, que la reconciliación entre dos grupos humanos no sucede por medio de la eliminación de los enemigos, o de uno de ellos, sino por medio de la muerte de la "enemistad". No se realiza por la supresión de los "actores del conflicto", sino por la desaparición del conflicto, o más exactamente, por la eliminación de sus causas. Por tanto, los procesos de reconciliación y paz entre grupos enemigos pueden recibir "nuevas luces" si se sustituye el paradigma que busca suprimir o reducir una de las partes -o "protagonistas del conflicto" - por otro que procure la eliminación del conflicto por medio de la supresión de sus causas.

De ahí que una verdadera teología de la reconciliación, así como debe partir del reconocimiento de la existencia de los diversos conflictos sociales, aspira a que logre su cometido en la resolución de las verdaderas causas que 
los produjeron, evitando caer en el falso irenismo o en la consolación con el más allá paradisíaco.

\section{Iniciativa de las víctimas}

En el actual lenguaje de reconciliación es frecuente la utilización de los términos: víctima y victimario, acepciones cuya etimología es discutida, pero que ciertamente están muy emparentados con la práctica de los sacrificios religiosos. Según la estudiosa Pilar Iñiguez, una de las mejores definiciones que engloba el concepto de víctima se ha dado en la Declaración de las Naciones Unidas (1961) sobre los principios de las víctimas del delito y del abuso del poder:

Es víctima toda persona que de forma individual o colectiva, haya sufrido daños, lesiones físicas o morales, cualquier tipo de sufrimiento emocional, pérdida financiera o menoscabo de cualquier derecho fundamental como consecuencia de acciones $\mathrm{u}$ omisiones que violen la legislación vigente de los estados miembros incluidos los que proscriben como abuso de poder.

La Sagrada Escritura establece dos procedimientos jurídicos para resolver los conflictos entre víctima y victimario: uno, llamado ríb (controversia bilateral), en el que intervienen solamente dos: el ofendido y el ofensor. Y el otro, denominado mispat (juicio propiamente forense), en el que interviene un tercero que es el juez, que dirime el conflicto mediante veredicto al que se someten ambos.

Para la Biblia, la aportación fundamental del rîb con respecto al mispat es la reconciliación entre víctima y victimario; el objetivo fundamental es que la víctima y el victimario restablezcan la justicia, es decir que"se reconcilien". Para el rîb, lo fundamental es la reconciliación y para que esta se dé, la víctima tiene que dar un primer paso y llamar al victimario para decirle"te ofrezco mi perdón" -porque en el momento en que le llama ya está ofreciendo el perdón-, y quiero que nos reconciliemos. Hay que tener cuidado, porque reconciliarse no significa olvidar lo que pasó, sino reintegrar lo que pasó en una relación distinta.

El rîb está apuntando en una dirección también útil, y es que la víctima puede favorecer, no solo la reconciliación, sino que la historia relacional puede ser más plena. Fíjense en qué dirección nos lleva el rîb; nos dice la Biblia en textos proféticos del AT, que el objetivo es la reconciliación, pero que, para que esta se dé, hay que pasar por un largo proceso en el que la víctima presente al victimario lo sucedido, pues se ha roto la relación de justicia; la víctima empieza ofreciendo el perdón, pero también la búsqueda de la verdad. Reconciliarse no es algo edulcorado, algo barato; primero hay que reconocer lo que ha pasado para intentar convencer al victimario de lo que ha hecho y de que reconozca y cambie -se conviertaante lo realizado. Pero hay un efecto de la justicia que quiere subrayar el rîb, y es que, lo importante para la víctima no es "derrotar y vencer" al victimario -lo que voy a decir no es un mero juego de palabras-, sino "convencerle de lo que ha hecho". Cuando la víctima presenta la acusación, lo que busca no es solo decir lo que ocurrió, sino también el reconocimiento de los hechos y el cambio, conversión. En el segundo momento del rîb, el victimario puede cambiar de dirección, después de escuchar los argumentos de la víctima. Y solo cuando se haya dado la acusación y el reconocimiento se puede dar la reconciliación. Por tanto, la reconciliación tiene mucho de restablecimiento de la dignidad de la víctima, de generosidad de la víctima, y también de conversión del victimario; todo eso forma parte de la reconciliación.

Si bien, idealmente se esperaría que el victimario sea quien busque a la víctima para reconciliarse, muchas, por no decir la mayoría de las veces, es la víctima quien decide sanar sus heridas para reconciliarse consigo misma. En el paradigma civil de la reconciliación de la antigüedad griega, el «papel» de la parte agresora consistía en buscar por todos los medios, incluso por medio del pago de un resarcimiento, el cese de las hostilidades; mientras que el «rol» de la parte ofendida consistía en mostrar benevolencia y abdicar de su ira contra la parte agresora. El paradigma paulino de la reconciliación invierte el orden convencional, haciendo de la parte ofendida aquella que facilita paradójicamente la reconciliación. Tal forma de comprender e interpretar la acción reconciliadora no tiene precedentes en la historia. Esto se evidencia tres textos paulinos (Col 1,22; 2 Co 5,18-20 y Rm 5,1-11), en los que la parte ofendida de la relación, renuncia o abdica sus cargos contra el agresor (enemigo y separado).

Así se percibe en la historia de Esaú y Jacob, de José y sus hermanos, y del padre misericordioso con sus hijos. La víctima, el agredido, el ofendido (Esaú, José, padre), son los que toman la iniciativa del perdón. 
Aunque el hijo pródigo haya decidido regresar, es el padre quien apenas viéndolo sale a recibirlo.Y fundamentalmente, esto se percibe en la muerte de Jesús, quien en medio del suplicio, él, como la víctima por excelencia, pide perdón por sus victimarios. En tal dirección van sus exhortaciones: "a quien te pegue en una mejilla muéstrale la otra", "si tu hermano peca llámalo a solas", "si no perdonan de corazón". Pero a la vez con su palabra y presencia, nos hace caer en cuenta de que somos victimarios, y debemos resarcir el daño: si cuando lleves tú ofrenda, te acuerdas que tu hermano tiene algo contra ti, ve primero y reconcíliate con él. O Zaqueo, que decide con la llegada de Jesús a la casa resarcir cuatro veces a quienes han sido víctimas de sus abusos.

La reconciliación entonces puede partir del perdón concedido por la víctima al victimario o por el perdón solicitado por el victimario a la víctima. El drama se desarrolla entre los dos y nadie más puede pretender perdonar o pedir perdón en nombre de ellos.

En la superación de la violencia la voz de las víctimas debe ser privilegiada, y su cultivo de la memoria, muy apreciado, pues son ellas las que encaman la posibilidad de la reconciliación. Antes que nada, a las víctimas se les debe escuchar. Son ellas las que tienen la posibilidad de perdonar y suyo es el derecho de no olvidar el mal que padecieron y que no puede repetirse. Pueden perdonar, olvidar no. La perspectiva de las víctimas debe cobrar especial importancia para comprender las implicaciones que tiene un proceso de reconciliación social en Colombia y para reconocer el papel que juegan en él la virtud política del perdón y el recurso profético de la memoria. Son las víctimas, con su capacidad para perdonar y mediante el cultivo sano de su memoria, las que pueden salvar a la sociedad de la crueldad violenta y del olvido indiferente.

\section{Memoria y verdad}

Establecer la verdad de lo que sucedió es uno de los primeros y más importantes pasos hacia la reconciliación. El recuerdo de lo sucedido es fundamental para sanar y reparar los daños causados. El profeta Natán le recordó a David su pecado contra Urías. El hijo pródigo se hizo consciente de su pecado, recordando lo realizado contra su padre; José fue llevando de manera pedagógica a sus hermanos a que recordaran lo que habían hecho; el Señor Jesús invita a recordar las ofensas cometidas contra los otros, antes de realizar el culto, y él mismo lleva a los discípulos de Emaús a recordar lo sucedido con él en Jerusalén, y a la vez les hace un repaso por la Sagrada Escritura. Además, cada vez que el resucitado se presenta a sus discípulos apela a su memoria mostrándoles las marcas de la crucifixión.

Iván Orozco (2002), citando al lingüista búlgaro-francés Tzvetan Teodorov (2000) -quien decía que si bien los victimarios quieren olvidar, tienen la obligación de recordar, mientras que las víctimas teniendo el derecho a olvidar no lo pueden hacer-, plantea que la única manera de evitar que la amnistía conduzca por el camino de la compensación anticipada de culpas a un olvido facilista sin capacidad de prevención, es compensando la eventual falta de castigo con una alta dosis de memoria y de verdad. De ahí que las comisiones de la verdad y no solo el castigo, son dispositivos para reforzar la memoria y la prevención, y si se quiere, para mejorar la calidad del olvido. Para que haya perdón es necesaria la verdad, y para que haya esta es necesario recuperar la memoria. Si no hubiese memoria, no habría tampoco verdad. Las víctimas saben cuán necesaria es la memoria para que brote la verdad. Hay que recordar; no hay que dejar que los hechos queden en el olvido, no simplemente por evitar caer en los mismos errores del pasado, sino especialmente porque desde la perspectiva de las víctimas, es necesario que se les haga justicia con la aparición de la verdad y de toda la verdad.

El derecho, a saber, hunde sus raíces en la historia de lo acontecido y equivale a que toda persona tenga acceso a la verdad y a su difusión pública para evitar que puedan reproducirse en el futuro las violaciones. Desde esta perspectiva, al Estado le corresponde, como parte del derecho a saber, el "deber de recordar", es decir, la obligación de garantizar las condiciones para el debate social acerca de los crímenes del pasado que evite en el futuro su revisión o su negación parcial o total. En el dilema entre una paz sin justicia punitiva plena y una justicia que no anticipe la paz, conviene reivindicar el papel profético de la memoria para poner la lucha legítima contra la impunidad a salvo de su asociación con la venganza y prevenir, a la vez, la indiferencia que viene del olvido. La memoria aparece entonces como recurso profético que mantiene vigente la exigencia de conocer la verdad de los hechos dolorosos en la lucha por la justicia. Por tanto, es un error pensar que la búsqueda 
de la verdad está referida solamente a intentos dañinos de"saldar cuentas con el pasado". La verdad está referida, por encima de todo, al futuro por construir, para lo cual es necesario hacer luz intensa sobre ese pasado que nunca más debe repetirse, no sea que nos vuelva a destruir.

\section{Búsqueda de la justicia}

La tradición bíblica presenta toda una legislación ordenada a preservar el derecho de las personas, y especialmente de los más pobres.Y en ese sentido se pronunciarán los profetas como centinelas de la alianza, exigiendo justicia. Medidas de protección, de alivio, de prevención, de punición, ordenadas a frenar el espiral de violencia, venganza y odio irracional, pero a la vez orientadas a la sanción reparadora de los culpables. De ahí que se diga que las tradiciones religiosas pueden ayudar a atenuar el odio y a fomentar la justicia, saliéndole al paso a los deseos de venganza mediante la implementación de sus códigos éticos y sancionatorios. El eje rector de la justicia es la rectificación. Esta debe proyectarse sobre un futuro de armonías y de sueños humanistas que deberían ser su contexto natural.

El Dios bíblico se revela, en la tercera manifestación de su nombre a Moisés, como un Dios compasivo (rahum) y bondadoso, lento para enojarse y pródigo en amor y fidelidad. La palabra utilizada aquí está vinculada al sustantivo plural, que en el AT suele designar la compasión y la misericordia: rahamim, y que deriva a su vez de rehem, el seno materno. Dios se define entonces, a sí mismo, con la imagen del amor entrañable de una madre, un amor total e incondicional. Cuando se apela a esta imagen de Dios, en los procesos de reconciliación, algunas personas mal intencionadas quieren manipular dicha imagen en aras de la impunidad de los victimarios. Y esto es contradictorio. Misericordia de Dios, no significa aval a la impunidad, al olvido. Bien dirá Ezequiel:

Pero si el impío se aparta de todos los pecados que ha cometido, guarda todos mis estatutos y practica el derecho y la justicia, ciertamente vivirá, no morirá2 ${ }^{2}$. Ninguna de las transgresiones que ha cometido le serán recordadas; por la justicia que ha practicado, vivirá23. ¿Acaso me complazco yo en la muerte del impío -- declara el Señor Dios -- y no en qué se aparte de sus caminos y viva? (Ez 18:21-23).

Y en la parábola del perdonado que no quiso perdonar, dice el evangelista mateo que: "Y enfurecido su señor, lo entregó a los verdugos hasta que pagara todo lo que le debía" (Mt 18: 34).

La tarea básica y primaria de cualquier fórmula que aspira a la justicia no es otra que el desafío por trazar la línea demarcadora entre quienes presidieron la comisión planificada de las múltiples atrocidades y los civiles que en condiciones de indefensión las sufrieron. Si el ejercicio de la justicia (retributiva, restaurativa o transicional) no es capaz de superar el victimismo indiferenciado, el que unas víctimas se compensan o justifican con otras y unos perpetradores hacen lo propio ante la existencia de sus adversarios, ello no es otra cosa sino el colapso de la justicia y la santificación de los vencedores.

\section{La fuerza del perdón}

Las tradiciones religiosas con sus diversos conceptos y métodos ayudan a no permanecer atados al pasado, sanando los recuerdos. La decisión del perdón puede estar basada en criterios pragmáticos. La asimilación del perdón como una decisión pragmática es más probable en cuanto se presente la declinación de las emociones, por lo que el tiempo desempeña un papel fundamental. Esto implicaría la posibilidad de un perdón unilateral, es decir, la posibilidad de que la víctima decida perdonar únicamente por los beneficios que eso le traería, pero sin ninguna consideración hacia el victimario. Si bien esto no solo es posible, sino que también es bastante probable en casos de procesos de reconciliación, el perdón bidireccional podría traer más beneficios en términos de reconstrucción de la convivencia.

El biblista Xabier Pikaza (2006), mostrando la novedad evangélica del perdón, plantea que frente a la ley del talión (¡a cada uno según su merecido!), el evangelio sitúa a los hombres ante el don y tarea del perdón, haciéndoles capaces de desactivar la bomba de violencia que amenaza con destruir la humanidad. En este sentido, cita a la antropóloga judía H. Arendt (1958), quien afirmó que el descubridor del papel del perdón en la esfera de los asuntos humanos fue Jesús de Nazaret. El hecho de que hiciera este descubrimiento en un contexto religioso y lo articulara en un lenguaje religioso, no es razón para tomarlo con menos seriedad en un sentido estrictamente secular. Continúa Pikaza afirmando que solo un perdón como el de Jesús (y el de otros hombres y mujeres de diversas religiones y culturas, que también perdonan gratuitamente) es capaz de romper el círculo del eterno retorno de una justicia que se cierra en sí mis- 
ma y perpetúa la ley de la fuerza. El perdón supera (¡no niega!) la lógica de la justicia (del talión que siempre se repite: ojo por ojo, diente por diente) y de esa manera puede liberar a los hombres y mujeres del automatismo de la violencia. Ese perdón solo puede partir de los excluidos del sistema de poder y de aquellos que se solidarizan con ellos.

Jesús no fue un profeta de conversión, no empezó pidiendo a los pobres manchados y pecadores que cambiaran de conducta, para recibir después (por ese cambio) el perdón de Dios, sino que ofreció comunión mesiánica o perdón, precisamente a los que, según ley, seguían siendo pecadores o manchados, sin exigirles conversión antecedente, pues sabía que solo el perdón ofrecido por gracia ( sin decir "yo te perdono" desde arriba!) puede cambiar a los" pecadores", no por cálculo de ley, sino por el poder de la misma gracia. Jesús, descubrió y propagó el perdón que nace desde abajo, desde los mismos condenados.

Si bien el perdón implica el encuentro entre el causante del dolor y el que lo ha sufrido y lo sigue sufriendo, esta visión condiciona el perdón a la voluntad de encuentro entre la víctima y el victimario, situación poco probable en el contexto colombiano y quizás, inconveniente, para las víctimas. De ahí la necesidad de hacer una diferenciación fundamental entre perdón y reconciliación, que permita ver el perdón como una capacidad que puede tener la víctima para liberarse del sufrimiento, sin depender del reconocimiento de culpa, del arrepentimiento, de la reparación o del propósito de no repetición por parte del victimario.

Es evidente que sin la cultura del perdón como virtud cívica, se seguirán atizando, en el ámbito mundial, nuevas violencias, nuevos terrorismos, nuevas guerras. Desafortunadamente, entre quienes están por la reconciliación que nos lleve a la paz, la mayoría piensa que la memoria que buscamos y la verdad que reclamamos pretenden solamente la reparación de las víctimas y el castigo de todos los delitos. Pero resulta que memoria y verdad también pueden llevar a reconocimiento de culpa por el victimario, a justicia transicional acompañada de perdón, que no siempre significa olvido, como piensan algunos al identificar perdón y olvido.

Todos los principios referidos anteriormente, junto con la reparación, configuran una unidad integral e indivisible. La carencia de una de estas instancias afecta profundamente a las otras, y su conjunto es la mejor aproximación a la Reconciliación.

\section{Conclusión}

Los conflictos entre los seres humanos no solo no son ajenos a la Biblia, sino que ella los tematiza y aborda por ser parte de la realidad y cotidianidad de las relaciones humano-sociales, a distintos niveles. Esto mismo hace que la necesidad de la reconciliación aparezca con insistencia y se presente a través de muchos y variados textos bíblicos que la refieren.

La obra reconciliadora llevada a cabo en Cristo Jesús se convierte en el llamado fundamental para que los creyentes, como sujetos de dicha reconciliación, sean los primeros instrumentos o embajadores de la misma. La reconciliación es la expresión más genuina de un verdadero seguimiento de Jesús. No es opcional o negociable, ella deriva de la fe en el crucificado resucitado. La tarea reconciliadora requiere un largo proceso, basado en principios que abogan no por una reconciliación de cualquier manera, sino por un verdadero proceso de reconciliación y sanación integral, que realice lo que utópicamente describen Isaías y Apocalipsis:

Is 11,6-9. El lobo morará con el cordero, y el leopardo se echará con el cabrito; el becerro, el leoncillo y el animal doméstico andarán juntos, y un niño los conducirá7. La vaca y la osa pacerán, sus crías se echarán juntas, y el león, como el buey, comerá paja ${ }^{8}$. El niño de pecho jugará junto a la cueva de la cobra, y el niño destetado extenderá su mano sobre la guarida de la víbora9 ${ }^{9}$ No dañarán ni destruirán en todo mi santo monte, porque la tierra estará llena del conocimiento del Señor, como las aguas cubren el mar.

Ap 21:1-4.Y vi un cielo nuevo y una tierra nueva, porque el primer cielo y la primera tierra pasaron, y el mar ya no existe ${ }^{2}$.Y vi la ciudad santa, la nueva Jerusalén, que descendía del cielo, de Dios, preparada como una novia ataviada para su esposo ${ }^{3}$. Entonces oí una gran voz que decía desde el trono: he aquí, el tabernáculo de Dios está entre los hombres, y Él habitará entre ellos y ellos serán su pueblo, y Dios mismo estará entre ellos ${ }^{4}$. Él enjugará toda lágrima de sus ojos, y ya no habrá muerte, ni habrá más duelo, ni clamor, ni dolor, porque las primeras cosas han pasado.

La reflexión bíblica sobre la reconciliación se hace más necesaria en el momento actual de post-acuerdo que está viviendo el país, y a la vez es una buena respuesta a la exigencia que se les está haciendo a los cristianos de aportar de manera constructiva a todo este proceso. 
De esta manera se constata que la palabra de Dios es viva, eficaz, y siempre tiene una palabra que decir, y una invitación que hacer, a los cristianos de los distintos lugares y momentos históricos, para que se articulen de manera decidida a los esfuerzos que se realizan por construir un mundo mejor.

\section{Referencias bibliográficas}

Agudelo, D. (2012). Apuntes para una comprensión moral sobre los marcos de la legalidad y las víctimas en Colombia. Revista Teología y Sociedad. Pontificia Universidad Javeriana Cali. 10, 100-109.

Bovati, P. (1997). Ristabilire la giustizia. Procedure, vocabolario, orientamienti (Analecta biblica 110). Editrice Pontificio Istituto Biblico. Roma.

Brown, R., Murphy, R. y Fitzmyer, J. (1971). Comentario San Jerónimo. Cristiandad. Madrid.

Castro Quiroga, L. A. (2006). Escenarios de reconciliación desde una teología espiritual y desde un país en conflicto. Pontificia Universidad Javeriana. Bogotá.

Cepeda Castro, I. y Girón Ortiz, C. (2004). Procesos públicos de esclarecimiento y justicia de crímenes contra la humanidad. Análisis político. 50, 53-71.

Dibo, G. (2002). Una práctica no violenta - Negociación de Abigail con David (1 Samuel 25). Ribl. 41, 29-38.

Figari, L. F. (1989). ¿Por qué una teología de la reconciliación?. Fondo Editorial. Lima.

Foulkes, I. (2006). Los códigos de deberes domésticos en Col 3,18-4,1 y Ef 5,22-6,9- Estrategias persuasivas, reacciones provocadas. Ribla. 55. Deuteropaulinas: un cuerpo extraño en el cuerpo paulino?. Quito, 60.

Garrido Rodriguez, E. (2008). El perdón en procesos de reconciliación: El mecanismo micropolítico del aprendizaje para la convivencia. Pap. Polit. 13, 123-167.

Gerleman, G. (1985).“IV'Slm. Tener suficiente”. En: E. Jenni, C.Westermann. Diccionario Teológico Manual del Antiguo Testamento. II. Cristiandad. Madrid.

Giraldo, J. (2007). Búsqueda de verdad y justicia. Seis experiencias. CINEP. Recuperado de: https://tuxdoc.com/download/giraldo-javier-busqueda-de-verdad-y-justicia pdf
Granados, J. M. (2007) Reconciliación, creación y rehabilitación. Aportes de la teología paulina a los procesos de reconciliación social. Theologica Xaveriana. (2007). 164, 517-532.

Guerrero, V. (2011). Justicia y paz desde la perspectiva de las víctimas. Consultado el 7 de abril de 2014. Recuperado de: http://wwww.voltairenet.org/librairie/article140071.html.

Herr, T (1994). Reconciliación en lugar de conflicto. Vida y espiritualidad. Lima.

Hoyos, G. (2003). El perdón es de lo imperdonable. Periódico El Tiempo (Consultado el 22. 10. 12).

Iñiguez Ortega, P (2003) La víctima: aspectos sustantivos y procesales. Tesis de doctorado. Universidad de Alicante. Recuperado de: http://www.lluisvives.com/serolet/ SirveObras/13560842112138384122202/013181 2.pdf.

IrrazabalL, G. (2014). Sean misericordiosos: La fe y la vida cristiana a la luz de la misericordia. Morali., 37,7-37.

Keener, C (2003). Some New Testament invitations to ethnic reconciliation. The Evangelical Quarterly. 75, 3, 195-213.

Langmead, R. (2008). Transformed relationships: reconciliation as the central model for the mission. Mission Studies. 25, 5-20.

López, E (2013). Perdonar sí, olvidar no. Una aproximación a la reconciliación en Colombia desde los sentimientos morales. Universitas Philosophica. 6, 85-96.

Martino, R (2003). Reconciliación y paz. II Congreso Nacional de Reconciliación: la reconciliación, el horizonte de la paz. Documentación de Pastoral Social. 196, 8-16.

Merkell, H. (2005). Katallaso - reconciliar. H. Balz, G. Schneider. Diccionario exegético del NT I. Sígueme. Salamanca.

Mueller Fahrenholdz, G. (1998) Turn to the God of Mercy: new perspectives on reconciliation and forgiveness. The ecumenical Rreview. 196-204.

Orozco Abad, I. (2002). La posguerra colombiana: divagaciones sobre la venganza, la justicia y la reconciliación. Análisis Político. 46, 78-99. 
Pikaza, X. (2006). Del perdón de las víctimas a la política del perdón. Atrio (Consultado el 17 de marzo de 2009). Recuperado de: $\underline{\text { http://2006.atrio.org/? } p=127}$

Sanz Gimenez, E. (2014). Los profetas y la justicia. Universidad Pontificia de Comillas. Madrid. Consultado el 4 de Noviembre de 2016. Recuperado de: https://web. unican.es/campuscultural/Documents/Aula\%20de\%20 estudios\%20sobre\%20religi\%C3\%B3n/CursoTeologiaCicloILosProfetasyLaJusticia2014-2015.pdf

Saravia, J. (2003). El Poblado de la Biblia. CLAR - CRC. Bogotá.

Schreiter, R. (2003). La religión como fuente y recurso para la reconciliación. Concilium. 303,129-138.

Sicre, J. (1984). Con los pobres de la tierra. La justicia social en los profetas de Israel. Cristiandad. Madrid.
Sicre, José Luis. (2003). Profetismo en Israel. El profeta. Los profetas. El mensaje. Estella (Navarra), Verbo divino.

Navarra, E. (2003). Profetismo en Israel. El profeta. Los profetas. El mensaje. Verbo divino.

Triana, P. Bases bíblicas para una teología de la reconciliación. Consultado el 7 de abril de 2014. Recuperado de:https://revtriana.wordpress.com/2011/11/11/ bases-biblicas-para-una-teologia-de-la-reconciliacion/

Vélez Caro, O. (2004). El método teológico. Bernard Lonergan y la teología de la liberación. 3. Ed. Facultad de Teología de la Pontificia Universidad Javeriana. Bogotá.

Villa, J. D. (2007). Si no fuera por Dios nosotros ya nos hubiéramos muerto. Víctimas, reconciliación y religión. Theologica Xaveriana. 164, 565-589. 